\title{
TORNAR-SE E PERTENCER: PROCESSOS DE GENERIFICAÇÃO NA ENGENHARIA ${ }^{1}$
}

\author{
BECOMING AND BELONGING: GENDERED PROCESSES \\ IN ENGINEERING
}

Wendy Faulkner

\begin{abstract}
Resumo:
O conceito de "generificação das culturas ocupacionais" pode ajudar a explicar as desigualdades de gênero e a segregação de gênero no trabalho - além dos fatores estruturais óbvios e extensamente reconhecidos. Isto permite que examinemos os fatores mais sutis e profundos que contribuem para fazer com que uma ocupação como a engenharia seja mais atrativa, confortável e suportável aos homens do que às mulheres. Dois fenômenos sociais são chaves para entender como as culturas ocupacionais são produzidas e generificadas: o complexo processo de socialização pelo qual as pessoas se tornam membros de uma comunidade ocupacional, e os vários marcadores pelos quais eles são compreendidos "para pertencer", como um "verdadeiro" engenheiro. O artigo explora ambos os fenômenos, com base em dados de entrevistas realizadas com mulheres engenheiras e com homens engenheiros na Escócia. Os dados destacam as várias maneiras pelas quais se tornar e pertencer pode ser generificado, em particular: a presunção de habilidades manuais, a invisibilidade de engenheiras-mulheres como engenheiras, a cultura social informal, e o código masculino do trabalho da engenharia (seja 'técnico' ou gerencial). Sobretudo, parece que as engenheiras têm mais propensão para perder a confiança e precisam esforçar-se mais do que os homens para conquistar a sociedade e serem reconhecidas "como engenheiras". O artigo conclui que estas questões são menos significativas entre os engenheiros-homens pela simples razão de que a engenharia é uma escolha mais autêntica para eles do que para mulheres. As implicações para as políticas que pretendem recrutar e reter mais mulheres na engenharia são exploradas.
\end{abstract}

Palavras-chave: Relações de gênero; Engenheiras; Processos de Generificação; Culturas Ocupacionais.

\begin{abstract}
The concept of 'gendered occupational cultures' can help explain gender inequality and gender segregation at work - beyond the obvious and widely acknowledged structural factors. It allows us to examine the more subtle and taken-for-granted factors which contribute to making an occupation like engineering more appealing, comfortable and supportive to (more) men than women. Two social phenomena are key to how occupational cultures are produced and, thus, gendered: the complex socialization process by which people 'become' members of an occupational community, and the various markers by which they are understood to 'belong', as a 'real' engineer. The paper explores both these phenomena, by drawing on interview data from women and men engineers in Scotland. The data highlight various ways in which becoming and belonging can be gendered, in particular: the presumption of hands-on tinkering skills, the invisibility of women engineers as engineers, the informal social culture, and the masculine coding of engineering work (be it 'technical' or managerial). Overall, it seems, women engineers are more likely to suffer losses of confidence and may struggle more than men to gain 'membership' as engineers. The paper concludes that these issues are less significant amongst men engineers for the simple reason that engineering is a more 'gender authentic' career choice for them than for women. The implications for policies intended to recruit and retain more women in engineering are explored.
\end{abstract}

Keywords: Gender Relations; Women Engineers; Gendered Processes; Occupational Cultures 


\section{Tornar-se e pertencer}

O conceito de 'culturas ocupacionais de Gênero' é útil para procurar compreender a segregação de gênero e a desigualdade no mercado de trabalho. Estou usando o conceito para capturar os fatores que não são estruturais - de modo especial nas engenharias (por exemplo, horário de trabalho prolongado e falta de práticas de funcionamento flexiveis). As 'culturas ocupacionais' incluem muitas dimensões possiveis: maneiras compartilhadas de pensar e de fazer o trabalho, a língua e os símbolos usados no trabalho, as interações sociais formais e informais com colegas, as brincadeiras, as histórias e as identidades compartilhadas, etc. O foco de 'gênero' obriga-nos a olhar os homens/masculinidades na engenharia, tanto quanto (se não mais do que) as mulheres - porque a maioria provavelmente tem papel mais importante para formar uma cultura ocupacional. O item-chave é identificar que aspectos de uma cultura ocupacional particular é mais atraente, mais confortável e dá mais suporte aos gêneros particulares (isto é, tipos particulares de homens e/ou de mulheres). Apesar do rótulo 'generificado', eu também estou procurando identificar aspectos das culturas ocupacionais que generificam - no sentido que eles 'produzem' ou executam gêneros particulares.

A questão central que eu proponho é como as culturas ocupacionais são (re)produzidas, e assim generificar/geneficando são processos de tornar-se e de pertencer. Fazer a escolha para ser um engenheiro é somente o primeiro passo para tornar-se um. Muitos anos são gastos na instrução e subseqüentemente são necessários na aprendizagem da prática antes que os engenheiros 'cheguem' a ser engenheiros totalmente desenvolvidos, tornando-se, no sentido que eu estou usando aqui, uma realização, envolvendo um longo e complexo processo de socialização profissional. A chave para essa realização é que uma sociedade estabelecida na comunidade ocupacional precisa ser compreendida pela comunidade para pertencer a ela, como um 'verdadeiro engenheiro'. Ganhar a especificidade da engenharia (como pensar e trabalhar de maneiras particulares) é uma pré-condição necessária, mas não suficiente para tornar-se membro; há diversos outros indicadores de pertencimento à engenharia.

Um trabalho prévio realizado nos Estados Unidos indica algumas das maneiras em que pertencer à engenharia está generificada - e algumas das conseqüências da generificação. A engenheira que se tornou socióloga, Karen Tonso (1997; 1999), conduziu uma série de estudos em uma faculdade de engenharia dos Estados Unidos. Analisando as fases nas quais estudantes de engenharia têm que passar, ela demonstrou que as estudantes de engenharia são visíveis como mulheres (sexualizada), mas invisíveis como engenheiras. $E$ por meio de observação participativa em design de projeto, ela encontrou algumas interações e práticas institucionais que também contribuem para esta invisibilidade, com o resultado de que algumas e engenheiras muito capazes não são reconhecidas por sua capacidade e esforço para encontrar bons empregos. Em um estudo baseado em entrevistas com mulheres e homens engenheiros no espaço de trabalho, Mcllwee e Robinson (1992) concluíram que 'ser visto como um engenheiro competente significa jogar-se em exposições ritualísticas na prática da competência técnica manual', mesmo quando o 
trabalho não exige esta competência. No geral, as engenheiras não pertencem a este indicativo informal. Em conseqüência, nas organizações em que a 'cultura da engenharia' é forte, e onde a promoção não é baseada em critérios formais, as engenheiras tendem a perder em termos de progressão na carreira.

Neste artigo, eu exploro algumas maneiras pelas quais os processos de tornar-se um engenheiro e pertencer à engenharia podem ser generificados. Eu extraio os dados de entrevistas com uma seção transversal das engenheiras e dos engenheiros que trabalham na Escócia, conduzido como parte de um estudo intitulado 'O gênero na/da engenharia'. Pelo fato desse estudo atualmente estar em desenvolvimento, os dados e a análise apresentados aqui são parciais e provisórios. Deve-se também notar que, embora os especialistas de ICT sejam incluidos no estudo, alguns dos pontos detalhados podem ser mais relevantes às disciplinas tradicionais da engenharia. Não obstante, eu estou confiante que todos os temas gerais explorados aqui são relevantes em algum grau, para ambas as comunidades.

\section{Tornando-se um engenheiro ou uma engenheira}

\section{Escolher ser um/a engenheiro/a}

Há notáveis semelhanças e diferenças nas razões porque as mulheres e os homens optam por uma carreira na engenharia. Todos são motivados por uma combinação de fatores. Na maioria dos casos, estes incluem o fato de que gostavam de Matemática e de Ciência na escola, vêem-se como pessoas 'práticas' e queriam uma boa carreira. Matemática e Ciências são naturalmente fundamentos necessários para a engenharia, mas é notável que as engenheiras, bem como os engenheiros, apreciam as regras e o caráter destes assuntos, que se justapõeM freqüentemente com assuntos como o inglês em que 'não há uma resposta correta'. A maioria das engenheiras são inspiradas e também excitadas pela tecnologia das engenharias, mesmo que uma proporção ligeiramente mais elevada de homens reportam o que Ruth Oldenziel (1999, p. 9) chama um 'amor pela tecnologia'. Presumivelmente, a maioria dos homens que obtém grau na engenharia gostam de algum modo de consertar, e a maioria das mulheres não.

Esta, no entanto, não foi a diferença mais significativa a emergir desta seção de minhas entrevistas com engenheiros. Como Ulf Mellström (1995), minhas entrevistas revelaram que a engenharia é em mais auto-evidente ou em meus termos um 'gênero autêntico' uma escolha mais evidente para homens do que para mulheres. Os homens que optam por ser engenheiros não são excepcionais, como homens. Certamente, muitos daqueles que eu entrevistei não forneceram nenhum ou quase nenhum motivo de sua escolha precisamente porque não há nada notável para um homem escolher ser um engenheiro. Em contra partida, virtualmente todas as mulheres que eu entrevistei têm uma história para contar sobre porque fizeram a escolha; o fato de uma mulher não ter filhos exige uma explicação. As reações das pessoas de fora são um lembrete constante que o fato de uma mulher ser engenheira 
(jovem ou velha) torna-as incomuns, notáveis. Muitas gostam muito de ser incomum, até rebeldes; e muitas são extremamente confiantes, do tipo que procura por desafios.

\section{Educação para a engenharia}

Neste contexto, foi importante para eu descobrir que muitas mulheres experimentam uma rápida perda de confiança ao entrar nos cursos de engenharia. Ambos, homens e mulheres estudantes acham os cursos de engenharia muito dificeis, e muitos são surpreendidos pelo nivel elevado do conteúdo de Matemática. O que surpreende é que as estudantes supõem frequentemente que todos são melhores que elas, que elas não são boas o bastante. Com o tempo, a maioria, como Jessica, percebe que 'nós somos todos iguais - bons em algumas coisas e ruins em outras'. E, com o tempo, muitos vão muito bem academicamente: é comum (em minha própria universidade pelo menos) encontrar números desproporcionais de mulheres que obtêm notas muito boas na engenharia (também Mcllwee e Robinson 1992).

As habilidades manuais práticas são um foco particular da baixa autoestima das mulheres que estudam engenharia - que é porque as experiências na reforma educacional gênero-inclusiva incluem tipicamente uma atenção maior a estes aspectos (por exemplo, Willoughby, 1999). As estudantes mulheres são também conscientes de que elas são 'vistas de fora como uma fêmea', especialmente aquelas que entraram antes de 1990. A experiência de Joanne na universidade é típica de muitas engenheiras:

O primeiro ano em particular, havia definitivamente esse sentimento de pisar fora da sua zona do conforto... e de algum modo supondo que todos soubessem mais do que eu. [Eu descobri que] muitos homens tiveram soldado ferros em casa... o que pareceu alienigena a mim!

Começar construir um rádio e colocá-lo para funcionar foi um grande estímulo à confiança de Joanne, mas ela nunca apreciou o trabalho manual e ainda (após 11 anos de trabalha) às vezes é arreliada pelos colegas masculinos por sua falta de habilidades para consertos.

\section{Aprendizagem na profissão}

Há muitas coisas que os engenheiros necessitam saber mas que não obtém da formação universitária - especialmente experiências relacionadas aos processos do trabalho, aos relacionamentos do trabalho e às matérias práticas. O conhecimento mais completo da engenharia é adquirido por meio do trabalho depois de alguns anos. Aos recém-graduados são dadas as tarefas mais simples, trabalhando próximo a outra pessoa. Enquanto adquirem experiência nos diferentes tipos de trabalho, eles vêem progressivamente melhor o quadro como um todo e ganham mais responsabilidade - para assim conhecer o processo inteiro. Há uma variação entre as empresas sobre supervisão formal e como o treinamento é estruturado. O grau de dificuldade ou não deste período depende muito do suporte e da capacidade de aproximação do instrutor individual ou do gerente. 
Fazer perguntas é o meio mais importante pelo qual os engenheiros aprendem no trabalho. Dos engenheiros recém-graduados é esperado que questionem seus colegas mais experientes, e ter seu trabalho avaliado. Certamente, fazer perguntas e rever o trabalho de cada um é uma parte da rotina no trabalho da engenharia, mesmo para engenheiros realmente experientes. Na prática, entretanto, cada engenheiro recém-formado descobre que há alguns colegas aos quais você não deve expor sua ignorância e outros que ficam felizes em responder as perguntas. E na prática, alguns engenheiros recém-formados são mais desinibidos do que outros para fazer perguntas que podem parecer perguntas 'ignorantes'. As engenheiras sênior relatam que aprenderam a sempre fazer as perguntas, no espírito do 'mantra' da Karen, 'não há nada pior que uma pergunta estúpida!'. Há uma idéia de que é menos provável que os engenheiros demonstrem que não sabem algo - isto é, são mais propensos a esconder sua ignorância - e ficam aliviados quando alguém (outro) faz a pergunta! Isto pôde também estar ligado à autenticidade de gênero - se para os homens é suposto ser 'naturais', as mulheres tem mais desculpas para não saber - ou pode apenas ser uma continuação da tendência de que mais meninas do que meninos fazem perguntas na escola.

Os homens e as mulheres têm que provar eles mesmo em seus primeiros anos como engenheiros, e isto traz, às vezes, muita ansiedade. 0 primeiro ano de Fiona como uma engenheira mecânica que trabalhava em uma companhia de manufaturas envolveu ser transferida em torno das diferentes partes da operação. Na ocasião, isto se transformou em uma espécie de experiência 'irritante', em que o que teve que provar não foi tanto sua habilidade em engenharia quanto disposição de rir das incômodas 'piadinhas' de cunho sexual - em outras palavras, sua habilidade de ser 'um dos caras'. Um desempenho equivalente ao, às vezes, exigido dos homens - uma 'prova de masculinidade' - especialmente nas interações com os operários ou os engenheiros técnicos, por exemplo, no local do edificio ou chão de fábrica. 0 engenheiro civil, Hamish, uma vez teve que demonstrar sua bravura ajustando uma explosão em uma mina potencialmente perigosa.

\section{Pertencer a engenharia}

A maioria das pessoas relatam que levam entre 4 a 7 anos antes que sintam que realmente 'chegaram' a ser um engenheiro completo. Ao longo do caminho há um número de momentos críticos em que os engenheiros experimentam um passo adiante em sua confiança profissional: admitindo que você está fazendo direito e que as pessoas estão fazendo perguntas a você, recebendo respostas positivas dos parceiros externos ou dos clientes, e realizando um projeto inteiro do começo ao fim. Tornar-se patente frequentemente marca o ponto final deste processo e é visto universalmente como um marco importante, digno de celebração.

Enquanto todos os engenheiros, mulheres e homens, fazem esforços de alguma forma durante estes anos iniciais de socialização, há algumas claras influências de gênero que facilitam que um se torne membro da sociedade na comunidade ocupacional, e que, feito um exame mais profundo, provavelmente 
esse processo é mais difícil para as mulheres do que para os homens.

\section{Visibilidade}

As experiências das engenheiras que eu entrevistei podem ser usadas para mostrar que elas são vistas primeiramente como mulher e depois como engenheiras. Contrário do que foi encontrado por Tonso, entretanto, a maioria reclama da falta de credibilidade que resulta da vida curta. Joanne, por exemplo, diz que 'Inicialmente, ser levada a sério é um desafio mais forte para mulheres.' E Karen, relata que 'como uma mulher mais velha, loira e com aparência jovial, as pessoas não me levam a sério no início. Mas uma vez que percebem que eu posso fazer o trabalho, isso muda.' Tais reclamações são naturalmente muito difíceis de avaliar empiricamente. Muito menos, a visibilidade representa uma outra etapa de trabalho que as mulheres e não os homens necessitem fazer antes que sejam vistas como engenheiras.

\section{Cultura Social Informal}

A cultura social informal dos locais de trabalho da engenharia pode ser completamente "laddish" - caracterizado pela conversa sobre esportes masculinos, o humour escorificado, xingamentos e a insinuação sexual ou heteronormativa. Tem-se que ter cuidado para não exagerar no caso. A maioria das interações sociais que eu observei parece respeitosa. Mesmo onde a cultura laddish é evidente, há outros (potencialmente mais inclusivo a gênero) tópicos da conversação e maneiras de interação. Nem todas as mulheres acham a cultura laddish incômoda, e nem todos os homens acham-na cômoda. Apesar de tudo, como indicado anteriormente, ser membro - para mulheres e homens - significa tornar-se 'um dos caras', em algum grau pelo menos. O caso extremo disso que eu observei está em uma companhia de serviços de óleo, em que mulheres e homens igualmente reconhecem que as mulheres que não 'se adaptam' e 'se ajustam'; nunca pertencem realmente ao grupo. E quando o trabalho é alto mar, 'ajustar-se' pode significar tolerar a presença difundida de tevê e de calendários pornográficos. Há uma hostilidade real para toda mulher que exercer seu direito de opor-se; 'Isto não é justo, quando houver somente uma mulher e 150 homens na plataforma!'

A cultura laddish é provavelmente mais marcada nos locais de trabalho onde há muita interação com operários, ou onde há muitos engenheiros jovens. Mas é de maneira nenhuma ausente em escritórios de engenharia que eu observei e fiquei sabendo no Reino Unido. O único lugar onde eu não encontrei uma cultura laddish foi em um escritório de desenvolvimento de software de uma companhia muito ciente da diversidade nos EUA. Aqui a cultura informal é normativa a gênero, mas é uma cultura centrada na família - tanto que as mulheres e os homens que não têm crianças às vezes se encontram trabalhando mais horas do que aqueles que têm filhos, porque não têm a 'desculpa' de sair para atender a suas crianças. 


\section{Autenticidade}

Foi dito a mim em forma de anedota que, onde um grupo de mulheres engenheiras tomou um drink ou dois, elas comumente confessam se sentir uma fraude. (Em minha experiência isto não é limitado às mulheres engenheiras!) Se esta fosse realmente uma experiência difundida, seria consistente com o caso da engenharia ser uma ocupação menos autêntica de gênero para mulheres do que para homens.

Para algumas mulheres engenheiras, parece que a falta de segurança ou senso de autenticidade continuam amarradas com o fato da prática, habilidades práticas. Sally tinha apenas começado seu primeiro emprego quando eu a entrevistei;

Quando eu vim aqui existia um elemento prático muito grande, então eu me senti completamente estúpida. ... Existe tanto que você não compreende quando você sai da universidade.

Para muitas mulheres engenheiras experientes, a relativa falta de habilidades práticas não é mais um caso de confiança. Como as mulheres entrevistadas por Mcllwee e Robinson, estas mulheres dizem que não estão apenas interessadas no lado prático da engenharia e indicam que habilidades de pensar são raramente requeridas em trabalhos profissionais da engenharia. Theresa, por exemplo, teve um raro conhecimento profundo na manutenção de carro, mas nunca se tornou (ou sentiu-se) tão boa quanto seus colegas masculinos, especialmente aqueles que tinham entrado por meio de estágios. Como muitas mulheres, Theresa dá importância às outras coisas em que ela é boa - em seu caso, desenvolvimento de negócio - que alguns dos homens pensadores não são: 'As pessoas ocupam sua área de conforto não?'

\section{O que conta como engenharia 'real'}

Um problema aparece com a abordagem de Theresa quando diferentes tipos de trabalho da engenharia não são todos considerados igualmente como verdadeira engenharia. Tipicamente, engenheiros têm dois discursos sobre isto. Um é uma estreita versão do tecnicismo no qual a engenharia é apresentada como 'porcas e parafusos', desenhos e cálculos. A outra é uma versão mais heterogênea, que compreende também relações interpessoais e vários aspectos de gerência de negócio. Há tensões profissionais, corporativas e de gênero em torno dessas duas versões do que se considera como engenharia.

Uma fonte de tensões de gênero é que as duas versões de engenharia são manifestadas em duas versões muito disponiveis de masculinidade. Um adota sua marca a partir do trabalho prático com tecnologia, e é moldado no engenheiro técnico - portanto 'porcas e parafusos'. O outro adota sua marca a partir da autoridade corporativa e comércio, e é moldado no gerente sênior ou homem de negócios (gênero intencional). Qualquer engenheiro-homem que progredir nestes últimos papéis pode perder suas credenciais como um engenheiro 'porcas e parafusos' aos olhos de colegas engenheiros, mas ele não perde suas credenciais como homem. De qualquer maneira, ele ganha 
nesta consideração, desde que a autoridade exercida como gerente e o dinheiro obtido no negócio sejam marcadores extensamente aprovados da realização em homens. Nos termos de Bob Connell, gerenciamento de alto nivel e papéis de negócios fornecem poderosos modelos da masculinidade hegemônica (1987).

Significativamente, nenhuma versão de engenharia - a tecnicista ou o heterogêneo - tem fortes associações femininas. No alto disto, o semprepresente dualismo técnico/social na engenharia é uma outra fonte da tensão de gênero, desde que 'o técnico' é prontamente associado com os homens e o 'o social' com mulheres, e os dois são considerados para ser mutuamente exclusivos (Faulkner, 2000b). Esta situação cria um paradoxo para mulheres engenheiras. Por um lado, sair dos rígidos papéis técnicos é visto como mais 'natural' (no sentido de autenticidade de gênero) para elas do que para homens - porque é amplamente assumido que mulheres engenheiras possuem melhor 'habilidades com pessoas' que os homens. Por outro lado, entrar em papéis de gerência e negócio de engenharia é visto como mais 'natural' aos homens engenheiros do que para mulheres, especialmente nos niveis mais elevados. $E$ porque a engenharia já é do ponto de vista de gênero inválido para mulheres, eu suspeito que aquelas mulheres que sobem a hierarquia (tão longe da engenharia 'porcas e parafusos') correm mais o risco de perder suas credenciais do que os homens que fazem o mesmo movimento.

\section{Dois casos: Claire e Karen}

Muitas das descobertas que eu acabei de rever são ilustradas pelos exemplos de Claire e de Karen. No princípio, havia muitas similaridades entre as duas mulheres. Ambas graduadas nos anos 1990s, assim estão agora em seu 30 s. Ambas têm como base a classe média. Ambas curtiram ser rebeldes escolhendo uma carreira diferente de seus pais. Ambas escolheram engenharia mecânica, embora nenhuma tivesse previamente qualquer socialização em engenharia 'prática'. Ambas esperaram que projeto em engenharia fornecesse alguma saida para seus talentos artísticos. Ambas estavam motivadas para fazer algo de valor social em seu trabalho. Ambas são voltadas para a carreira e ambiciosas. No evento, as experiências de Claire e de Karen de transformarse em um engenheiro e os caminhos de suas carreiras foram bem diferentes. Entretanto, cada uma delas esforçou-se de maneira diferente em torno das questões de 'pertencimento' como uma engenheira.

\section{Claire}

Claire ficou imediatamente decepcionada quando ela começou na universidade: 'tudo era matemática', e muito pouco projeto. Ela achou matemática 'muito, muito dificil', embora começasse ser boa nisso e mais tarde se sentisse orgulhosa que tinha podido enfrentar o desafio da graduação. Mais desesperador de tudo, ela sentiu que havia sempre uma distância entre os cálculos e qualquer coisa prática - ela 'não poderia relacioná-los a qualquer 
coisa real'. Como muitos outros, ela estava 'tão desfamiliarizada com o [trabalho prático], eu achei-o completamente assustador e completamente dificil de se lidar com'. O efeito combinado disto e da lacuna que ela experimentou foi uma acusação condenável de sua educação: 'Corrói sua confiança, porque... eu tenho este grau em engenharia mas realmente eu não poderia usar!'

$\mathrm{Na}$ ocasião, o primeiro emprego de Claire foi um posto de pesquisa em sua universidade em engenharia auxiliada por computador, o que a levou a um PhD. Isto ajudou a recuperar sua confiança: seu supervisor a apoiava, e o projeto levou-a a companhias de ferramentas de máquinas, incluindo seis meses no exterior em uma empresa, isso contribuiu para sua experiência prática. Ela diz de si mesma que ela não é muito boa no planejamento de carreira. Após o trabalho de pesquisa, ela ensinou engenharia auxiliada por computador em outras universidades por quatro anos. Ela parou porque era pedido a ela para ensinar fora de sua especialidade.

Seu trabalho atual foi uma considerável mudança. Nos últimos 5 anos, Claire tem trabalhado em uma empresa de princípio de pesquisa e desenvolvimento P\&D, desenvolvendo tecnologias médicas, nas quais ela é responsável por 'colocar sistemas de informação para dar suporte a negócios' em ambos os lados de engenharia e gerenciamento. Isto inclui muita programação e outros trabalhos técnicos como desenvolvimento de processo, treinamento e supervisão de quatro equipes. Apesar do elevado conteúdo técnico, Claire apresentou-se a mim como não fazendo 'um trabalho profissional de engenharia'. Ela renunciou sua tão difícil conquista de membro do Instituto de Engenheiros Mecânicos, o que fez ela sentir-se 'um pouco' triste e com 'um pequeno pesar'. E ela suspeita que os engenheiros da empresa realmente não a vêem como sendo um deles. No entanto, ela gosta de seu trabalho atual e está iniciando o desafio de compreender melhor o lado dos negócios fazendo um MBA em meio período.

\section{Karen}

Karen escolheu uma graduação em engenharia arquitetural, que foi ensinada parcialmente por arquitetos; assim, teve 'mais projeto e menos matemática' do que o curso normal de engenharia. Ela teve tempos felizes na universidade, ao contrário de Claire, embora tenha 'odiado' assuntos como controles e microprocessadores, 'porque eles não envolviam pessoas como os prédios comerciais fazem'. Mais planejadora da carreira do que Claire, ela juntou-se ao escritório principal de uma companhia multinacional de consultoria em desenvolvimento de edifícios com o esquema de treinamento de graduação. Seu gerente imediato subjugou sua competência, porque ele não tinha muita confiança na competência dela para desenvolver os trabalhos, mas então ela mudou para um outro 'quem diria que eu poderia fazer isto'.

Karen foi uma empreendedora de nível elevado. Em seu quinto ano na companhia, ela era responsável por projetar todos os serviços mecânicos do edifício no principal ícone da construção, incorporando muitos principios de sustentabilidade. Subseqüentemente, ela ganhou um prêmio nacional de prestigio por este trabalho, tornou-se certificada e obteve sua primeira promoção 
na companhia, sinalizando que ela estava pronta para o negócio e para executar projetos sem ajuda. No entanto, recentemente Karen deixou a companhia na qual teve uma precoce brilhante carreira, para trabalhar em gerência de projetos.

Sua partida seguiu em mudança para um escritório regional da companhia. Neste escritório, espera-se que todos os engenheiros façam um pouco de tudo, incluindo o trabalho de 'pano de fundo' de um projeto detalhado. Karen ressentiu-se por isto; ela já tinha provado para si mesma que projeto detalhado não é o lugar onde suas forças ou interesses pessoais se encontram. Embora ela fosse altamente avaliada e respeitada por suas habilidades em projeto conceitual e ganhando novos negócios, não foi permitido a ela se concentrar no trabalho que ela gosta. Além disso, o desinteresse de Karen em fazer trabalho de projeto detalhado provavelmente questionou suas credenciais de engenheira entre alguns no escritório central. Apesar do fato que virtualmente toda a equipe executa ambos papéis, de frente e no pano de fundo, a maioria daqueles que eu observei realizavam na prática a versão da engenharia 'porcas e parafusos'. Houve uns arfares de surpresa quando ela admitiu que nunca 'dimensionou' uma tubulação de gás - 'Você chegou tão longe e nunca dimensionou uma tubulação do gás?!'.

\section{Conclusões e implicações}

Meu argumento central é que os casos de confiança e pertencimento ao grupo destacadas pelos exemplos de Claire e de Karen serão de modo geral experimentadas em menor profundidade por homens engenheiros precisamente porque a engenharia é uma opção de carreira mais autêntica de gênero para eles do que para as mulheres. A evidência apresentada aqui destaca diversos elementos que juntos conspiram para generificar o processo de tornar-se e pertecer: a ousadia de habilidades manuais, a invisibilidade das mulheres engenheiras como engenheiras, a cultura social informal, e o código masculino de trabalho de engenharia (seja ‘técnico' ou gerencial). Eu acredito que todos estes elementos são sintomáticos do fato que a engenharia foi, por muito tempo, fortemente dominada por homens. Mais precisamente, eu acredito que eles refletem uma mão-dupla, mutuamente reforçando o relacionamento entre a presença das culturas ocupacionais que favorecem ou são mais confortáveis aos homens, e a predominância numérica contínua dos homens na engenharia.

O desafio, para os esforços de recrutar mais mulheres para engenharia, é como quebrar esse circuito. Vivian Lagesen (em breve) tem discutido recentemente que a 'força dos números' importa muito, e eu concordo com ela. Seu próximo estudo sobre as campanhas de recrutamento do NTNU em Trondheim, Noruega, demonstra que as medidas mais cruciais são aquelas que diretamente aumentam os números das mulheres que entram na informática e nos cursos de engenharia (como quotas), o que torna visivel a presença das mulheres nestes campos. Eu argumentaria que tal medida é muito eficaz porque se volta na direção da engenharia 'normalizada' como uma escolha de carreira 
para mulheres - assim começa a desobstruir o que eu acredito ser a base da origem para a autenticidade de gênero.

Melhorar a permanência e a progressão na carreira das mulheres em campos da engenharia levanta diferentes desafios e exige diferentes tipos de medidas. Nós vimos que medidas de suporte e de intervenção são necessárias em muitos pontos críticos ao longo do trajeto de tornar-se um engenheiro. $\mathrm{Na}$ educação universitária, há a necessidade de maior atenção às habilidades e aos projetos práticos, e a de relacionar o núcleo matemático aos desafios tecnológicos do cotidiano. Nas companhias, há a necessidade de melhorar treinamento dos mentores e gerentes de modo que os engenheiros juniores sejam auxiliados mais consistentemente - por exemplo, por meio da promoção de um clima no qual 'não existe nenhuma pergunta boba' - e de modo que os engenheiros em todos os estágios tenham uma adequada supervisão e aconselhamento sobre a progressão de suas carreiras.

A maioria, senão todas estas medidas seria boa para os homens engenheiros assim como para as mulheres, e bom para a engenharia como profissão. Um tanto mais dificeis de interromper são os casos que cercam as culturas sociais informais na engenharia, e os limites preocupantes sobre o que constitui a engenharia 'real'. Com respeito ao formador, há uma necessidade argumentável para um cuidadoso treinamento de diversidade, do tipo usado em algumas empresas dos E.U.A., para incentivar uma cultura informal mais inclusiva sem gerar ressentimento entre o grupo da maioria. A última demandará, na linguagem dos estudos feministas da tecnologia, novas 'coconstruções' de ambos, gênero e engenharia.

\section{Referências}

BIJKER, W. E., Hughes, T. P.; PINCH, T. J. The Social Construction of Technological Systems, MIT Press, Cambridge, MA, 1987.

CONNELL, R., Gender and Power: Society, the Person and Sexual Politics, Polity Press, Cambridge, UK. 1987.

FAULKNER, W. 'The power and the pleasure? A research agenda for "making gender stick" to engineers'. In: Science, Technology, \& Human Values, vol. 25, n. 1, 2000a, pp. 87-119.

FAULKNER, W., 'Dualisms, hierarchies and gender in engineering', Social Studies of Science, vol. 30, n०. 5, 2000b, pp. 759-92.

LAGENSEN, V. Forthcoming, 'The strength of numbers: Strategies to include women into computer science', Social Studies of Science.

MCILWEE, J. S.; ROBINSON, J.G., Women in Engineering, SUNY Press, Albany, NY, 1992.

MELLSTRÖM, U. Engineering lives, Technology \& Social Change (Tema T), Linköping University, Linköping, Sweden, 1995.

OLDENZIEL, R. Making technology masculine: Men, Women and Modern Machines in America, 1870-1945, Amsterdam University Press, Amsterdam, 1999.

TONSO, K. 'Constructing engineers through practice', PhD thesis, University of Colorado at Boulder, 1997.

TONSO, K.L. 'Engineering gender - gendering engineering: A cultural model for belonging. Journal of Women and Minorities in Science and Engineering, vol. 5, $n^{\circ} .4,1999, \mathrm{pp}$. 365-404. 

EU Leonardo da Vinci programme Curriculum-Women-Technology project, Leeds Metropolitan University, Leeds.

1 Traduzido do original "Becoming and belonging:Gendered processes in engineering" publicado no livro The Gender Politics of ICT organizado por Jacqueline Archibald, Judy Emms, Frances Brundy. Eva Turner. Tradução de Lindamir Salete Casagrande e Juliana Schwartz. Revisão de Sonia Ana Leszczynski. Agradecemos a autora pela autorização da tradução.

2 Senior Lecturer, Science Studies Unit, Department of Sociology, University of Edinburgh.

3 Uma indicação das perguntas moldar e de pesquisa do estudo pode ser encontrada em Faulkner (2000a). Eu reconheço grata a sustentação financeira do conselho de pesquisa econômico e social para este estudo (referência: RES-000-23-0151). Os agradecimentos são também devido aos muitos engenheiros que generosamente deram suas horas para compartilhar as suas experiências comigo e (no exemplo daqueles citados aqui) que concordaram que suas histórias fossem publicadas. No total uns 50 engenheiros foram entrevistados para este estudo, e a observação foi conduzida em três momentos projetando - um deles no desenvolvimento do software. As entrevistas que eu extraio foram conduzidas em 2004; a maioria fizeram exame pelo menos de uma hora e foram gravados.

4 O trabalho de Tonso é muito importante nesta consideração porque, como uma engenheira experiente ela mesma podia fazer as aproximações e interações entre engenheiras e identificar quando as contribuições valiosas não foram reconhecidas.

5 Laddish é palavra inglesa e que não possui uma palavra em português que possa traduzir seu significado. Ela diz respeito ao comportamento observado em jovens do sexo masculino quando eles estão juntos e sem presença feminina. Exemplos desse comportamento são ficar bêbado, xingar uns aos outros, referências a futebol e mulheres.

6 Eu usei o termo heterogênio no sentido cunhado pelos sociólogos da tecnologia: para conduzir de modo compacto combinado, 'web sem costuras' de elementos sociais e técnicos em todos os artefatos e atividades tecnológicas (Bikjer, Hughes \& Pinch 1987). 